\title{
Potency of nondepolarizing muscle relaxants on muscle-type acetylcholine receptors in denervated mouse skeletal muscle
}

\author{
Hong WANG ${ }^{1,2}$, Bin YANG ${ }^{1}$, Guang-wei HAN ${ }^{1}$, Shi-tong $\mathrm{LI}^{1, \text { * }}$ \\ ${ }^{1}$ Department of Anesthesiology, First People's Hospital, School of Medicine, Shanghai Jiao Tong University, Shanghai 200030, China; \\ ${ }^{2}$ Department of Anesthesiology, the First Affiliated Hospital of Bengbu Medical College, Bengbu 233004, China
}

\begin{abstract}
Aim: To investigate the changing resistance to nondepolarizing muscle relaxants (NDMRs) during the first month after denervation. Methods: The denervated and innervated skeletal muscle cells were examined on days 1, 4, 7, 14, 21, and 28 after denervation. Individual denervated and innervated cells were prepared from the flexor digitorum brevis of the surgically denervated and contralateral hind feet, respectively. Nicotinic acetylcholine receptors (nAChRs) in the cells were activated with $30 \mu \mathrm{mol} / \mathrm{L}$ acetylcholine, either alone or in combination with various concentrations of vecuronium. Currents were recorded using a whole-cell patch-clamp technique. Results: The concentrations of vecuronium resulting in half-maximal inhibitory responses $\left(\mathrm{IC}_{50}\right)$ increased $1.2-(P>0.05)$, 1.7-, 3.7-, 2.5-, 1.9-, and 1.8-fold ( $P<0.05)$ at Days 1, 4, 7, 14, 21, and 28 after denervation, respectively, compared to the innervated control. Resistance to vecuronium appeared at Day 4, peaked at Day 7, and declined at Day 14 after denervation. Nevertheless, IC $\mathrm{C}_{50}$ values at Day 28 remained significantly higher than those for the innervated control, suggesting that the resistance to vecuronium had not disappeared at Day 28.

Conclusion: The NDMR doses required to achieve satisfactory clinical effects differ at different times after muscle denervation.
\end{abstract}

Keywords: denervation; nondepolarizing muscle relaxants; nicotinic acetylcholine receptors; skeletal muscle cells; vecuronium

Acta Pharmacologica Sinica (2010) 31: 1541-1546; doi: 10.1038/aps.2010.163; published online 22 Nov 2010

\section{Introduction}

At the neuromuscular junction (NMJ), the motor end-plate (sarcolemma of the postsynaptic surface) contains a high density of nicotinic acetylcholine receptors (nAChRs). When these receptors are activated by presynaptically released acetylcholine $(\mathrm{ACh})$, cations are permitted to flow through the $\mathrm{AAChR}$ pore, leading to depolarization of the muscle membrane and creating an end-plate potential. If the end-plate potential is large enough, an action potential is evoked and ultimately causes muscle contraction. Clinically used nondepolarizing muscle relaxants (NDMRs), typified by $d$-tubocurarine (dTC), competitively occupy the $a_{\delta}$ and $a_{\varepsilon}\left(\right.$ or $\left.a_{\gamma}\right)$ sites of nAChRs to achieve muscle relaxation during surgery and anesthesia.

nAChRs include two subtypes: the adult form ( $\varepsilon-A C h R)$, composed of $a_{2} \beta \delta \varepsilon$ subunits, and the fetal form ( $\left.\gamma-A C h R\right)$, containing $\alpha_{2} \beta \delta \gamma$ subunits ${ }^{[1,2]}$. The two subtypes have different electrophysiological properties: $\varepsilon$-AChR manifests a larger

\footnotetext{
* To whom correspondence should be addressed.

E-mail wh201071@gmail.com

Received 2010-03-18 Accepted 2010-08-16
}

slope conductance and a much shorter mean open channel time than $\mathrm{\gamma}-\mathrm{AChR}^{[3]}$. $\mathrm{\gamma}$-AChR is initially expressed in fetal muscle and is then replaced by $\varepsilon$-AChR when muscles are innervated. However, after denervation of adult muscles, $\mathrm{\gamma}$-AChR is expressed de novo throughout the muscle membrane $^{[4]}$.

Thermal injury and other forms of critical tissue damage can cause denervation changes in skeletal muscle. Denervated skeletal muscle displays aberrant responses to muscle relaxants, including lethal hyperkalemia in response to the depolarizing muscle relaxant succinylcholine and resistance to NDMRs, which coincide with the up-regulation of nAChRs and $\gamma$-AChRs on the muscle membrane ${ }^{[5-9]}$. After denervation, the amounts of $\mathrm{nAChR}$ and $\mathrm{\gamma}$-AChR change with time; furthermore, the $\mathrm{IC}_{50}$ of dTC correlates positively with $\mathrm{nAChR}$ and $\mathrm{\gamma}$-AChR mRNA levels at different times after denervation $^{[9-11]}$. All of these results indicate that the NDMR doses required to achieve satisfactory clinical effects may differ at different times after denervation. The aim of this study was to measure the changes in the potency of NDMRs during the first month after denervation in a mouse model. 


\section{Materials and methods Denervation}

This study was approved by the Animal Care and Use Committee of the Shanghai JiaoTong University School of Medicine. Balb/c mice (35 days old) were anesthetized with pentobarbital, $40 \mathrm{mg} / \mathrm{kg}$ ip. A few $\mathrm{mm}$ of the right sciatic nerve was excised through a small (3-5 $\mathrm{mm})$ incision over the hip. The incision was sutured with a single stitch. Animals were killed at $1,4,7,14,21$, or 28 days after denervation by pentobarbital anesthesia and cervical dislocation. The left leg of each mouse served as the innervated control.

\section{Isolation of muscle fibers}

Single skeletal muscle cells from the flexor digitorum brevis (FDB) muscle were obtained from the hind feet of each mouse. The muscles were incubated for $3 \mathrm{~h}$ with Dulbecco's modified Eagle's medium (DMEM) (Invitrogen ${ }^{\mathrm{TM}}$, Grand Island, NY, USA) containing 10\% fetal calf serum (Invitrogen ${ }^{\mathrm{TM}}$, Grand Island, NY, USA), 100 units/mL penicillin, $100 \mu \mathrm{g} / \mathrm{mL}$ streptomycin, and $0.2 \%$ collagenase $1 \mathrm{~A}$ (Sigma Chemical Co, Saint Louis, USA) in a shaking bath at $37^{\circ} \mathrm{C}$. After $3 \mathrm{~h}$ of enzymatic treatment, the muscles were dissociated into single muscle cells using Pasteur pipettes with different tip sizes.

\section{Electrophysiology}

FDB muscle cells were voltage-clamped using a whole-cell patch-clamp technique ${ }^{[12]}$. All experiments were performed at room temperature $\left(20-24^{\circ} \mathrm{C}\right)$. Patch pipettes were pulled from borosilicate glass using a Flaming Brown micropipette puller (P97; Sutter Instrument Co, Novato, CA, USA), ranging from 1 to $2 \mathrm{M} \Omega$. The pipette electrode was filled with the following solution (mmol/L): $140 \mathrm{KCl}, 10 \mathrm{HEPES}, 10 \mathrm{EGTA}, 1 \mathrm{CaCl}_{2}$, and $1 \mathrm{MgCl}_{2}$; the $\mathrm{pH}$ was adjusted to 7.2 with $\mathrm{KOH}$. The external solution contained (mmol/L) $5 \mathrm{KCl}, 140 \mathrm{NaCl}, 1 \mathrm{CaCl}_{2}, 1.25$ $\mathrm{MgCl}_{2}, 10 \mathrm{HEPES}$, and 10 glucose, with $0.5 \mu \mathrm{mol} / \mathrm{L}$ atropine sulfate, and the $\mathrm{pH}$ was adjusted to 7.4 with $\mathrm{NaOH}$. The cells were voltage-clamped at $-80 \mathrm{mV}$ in a whole-cell configuration after obtaining G $\Omega$ seals. Much $(60 \%-80 \%)$ of the series resistance was compensated. Currents were recorded with an EPC10 amplifier (HEKA Elektronik, Germany) and PatchMaster software (HEKA Elektronik, Germany), sampled at $10 \mathrm{kHz}$, and stored on a computer.

ACh and atropine sulfate were purchased from Sigma (Saint Louis, USA). Vecuronium (NV Organon, The Netherlands) was obtained from a preparation for clinical use. All drugs were dissolved in the external solution and were applied by a gravity-driven perfusion system. Solutions and subsequent dilutions were prepared immediately before the experiments.

Test solution applications containing either ACh alone or in combination with various concentrations of vecuronium were applied for $10 \mathrm{~s}$ to the skeletal muscle cells, and the peak current was determined. To determine the effect of vecuronium on the ACh-elicited current, the solution containing the vecuronium perfused the skeletal muscle cells for 3 min prior to the application of ACh. The washout time between each drug application was at least $60 \mathrm{~s}$ in order to minimize the amount of desensitization throughout the course of an experiment. Currents were acquired from five skeletal muscle cells taken from at least two mice. The control current caused by ACh alone was measured again after washout of the vecuronium. Taking the mean value of these two ACh applications as the average control current, the antagonist response (percentage inhibition of average control current) was calculated using the following equation:

$$
\% \text { Inhibition }=100 \times\left(1-\frac{\text { Current in presence of antagonist }}{\text { Average control current }}\right)
$$

\section{Statistical analysis}

Data analysis was performed off-line using Origin 8 (OriginLab, Northampton, MA, USA) and GraphPad Prism 4 (GraphPad software, Inc, San Diego, CA, USA). Concentrationresponse curves were fitted to the four-parameter logistic equation by nonlinear regression analysis, and $\mathrm{IC}_{50}$ values were determined. Statistical significance was assessed with one-way analysis of variance followed by Tukey's test. $P<0.05$ was considered significant.

\section{Results}

ACh at different concentrations (1-500 $\mu \mathrm{mol} / \mathrm{L})$ was applied for $10 \mathrm{~s}$ to mouse skeletal muscle cells without denervation. ACh elicited concentration-dependent inward currents. The data were fitted to a logistic equation. The ACh concentration producing $50 \%$ of the maximal response $\left(\mathrm{EC}_{50}\right)$ was 27.1 $\mu \mathrm{mol} / \mathrm{L}$ for the $\mathrm{nAChR}$ in the innervated skeletal muscle (Figure 1; Hill coefficient=2.14). In all following experiments, a concentration of $30 \mu \mathrm{mol} / \mathrm{L}$ was used to activate $\mathrm{nAChR}$ because this concentration was close to the $\mathrm{EC}_{50}$ concentration and produced large and robust responses.

Application of $30 \mu \mathrm{mol} / \mathrm{L} \mathrm{ACh}$ produced inward currents with different amplitudes at the $\mathrm{nAChRs}$ of denervated and control (innervated) skeletal muscle cells on Days 1, 4, 7, 14, 21 , and 28 after denervation. Compared with the responses of control cells, responses induced by $30 \mu \mathrm{mol} / \mathrm{L}$ ACh after denervation increased 1.8-, 4.0-, 6.7-, 4.5-, 3.3-, and 3.0-fold $(P<0.01)$ at days $1,4,7,14,21$, and 28 , respectively (Figure 2$)$.

Vecuronium reversibly inhibited inward currents elicited by the application of ACh $(30 \mu \mathrm{mol} / \mathrm{L})$ on denervated and control skeletal muscle cells in a concentration-dependent manner at days 1, 4, 7, 14, 21, and 28 after denervation (Figure 3 and 4). Compared with the $\mathrm{IC}_{50}$ values of vecuronium for the control, the $\mathrm{IC}_{50}$ values were 1.2- ( $\left.P>0.05\right), 1.7-, 3.7-, 2.5-, 1.9-$, and 1.8fold greater $(P<0.05)$ at Days $1,4,7,14,21$, and 28 after denervation, respectively (Table 1 ).

\section{Discussion}

Determination of the altered potencies of NDMRs on nAChRs in the short-term after denervation of skeletal muscle is important from a clinical viewpoint because the amount of membrane $\mathrm{nAChR}$ and the proportion of $\mathrm{\gamma}$-AChR after denervation change with time, which may lead to altered dosing requirements of NDMRs to achieve the desired effect. 

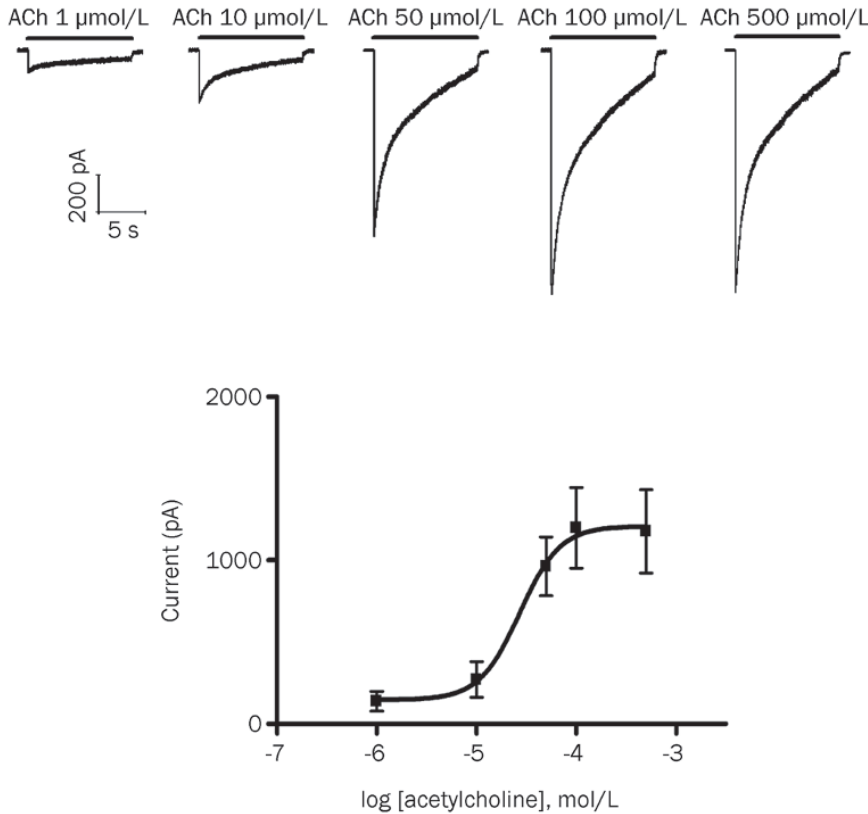

Figure 1. Acetylcholine (ACh) produced concentration-dependent inward currents in the innervated skeletal muscles. (Top) Representative recording of currents produced by 1, 10, 50, 100, and $500 \mu \mathrm{mol} / \mathrm{L} \mathrm{ACh}$ (horizontal bars). (Lower) Concentration-response curve for the action of ACh on adult-type nicotinic acetylcholine receptors ( $\varepsilon$-nAChRs). Data points show means $\pm S D$ (error bars) of five muscle cells taken from at least two mice.

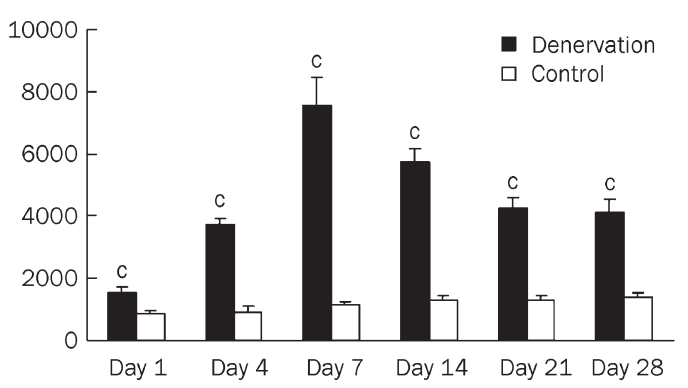

Figure 2. Responses were elicited by the same concentration of acetylcholine (30 $\mathrm{\mu mol} / \mathrm{L})$ on denervated and control (innervated) skeletal muscle cells at Day $1,4,7,14,21$, and 28 after denervation $(n=5) .{ }^{c} P<0.01$ vs Control.

This study involved the dynamic observation of the potencies of NDMRs at different times after muscle denervation. We first established the action of acetylcholine on $\mathrm{nAChR}$ in the skeletal muscle of the innervated controls. Interestingly, the $\mathrm{EC}_{50}$ value of $\mathrm{ACh}$ we determined was greater than values obtained in previous studies ${ }^{[13,14]}$. This disagreement may result from a discrepancy in the endogenous nature of the nAChR between mouse skeletal muscle and the Xenopus laevis oocytes used in other research. The process by which the adult mouse muscle nAChR was heterologously expressed in Xenopus laevis oocytes may lead to minor differences in glycosylation or other posttranslational modifications. Looking at previous reports of single channel recordings of $\varepsilon-\mathrm{AChR}$,
Table 1. Potencies of vecuronium at nicotinic acetylcholine receptors in denervated and innervated skeletal muscle cells at different time points after denervation.

\begin{tabular}{|c|c|c|c|c|c|}
\hline \multirow[b]{2}{*}{ Group } & \multicolumn{2}{|c|}{$\mathrm{IC}_{50}(\mathrm{nmol} / \mathrm{L})(95 \% \mathrm{Cl})$} & \multirow[b]{2}{*}{$P$ value } & \multicolumn{2}{|c|}{ Hill coefficient } \\
\hline & Denervation & Control & & $\begin{array}{l}\text { Dener- } \\
\text { vation }\end{array}$ & Control \\
\hline Day 1 & 11.7 (4.6-29.9) & $9.4(3.7-23.8)$ & $>0.05$ & 0.99 & 1 \\
\hline Day 4 & $20.0(10.8-37.0)$ & $11.5(3.4-38.2)$ & $<0.01$ & 1.27 & 1.15 \\
\hline Day 7 & $35.7(16.2-78.5)$ & $9.6(3.9-23.7)$ & $<0.01$ & 1.33 & 0.97 \\
\hline Day 14 & $28.8(18.1-45.6)$ & $11.5(5.4-24.5)$ & $<0.01$ & 1.22 & 0.95 \\
\hline Day 21 & $23.5(13.8-40.4)$ & $12.5(5.6-27.6)$ & $<0.01$ & 1.19 & 1.03 \\
\hline Day 28 & $23.3(15.6-34.7)$ & $13.2(4.8-36.1)$ & $<0.05$ & 1.12 & 1.07 \\
\hline
\end{tabular}

Potencies of vecuronium at nicotinic acetylcholine receptors (nAChRs) are expressed as the value achieving $50 \%$ of maximal inhibition $\left(\mathrm{IC}_{50}\right)$ of the inward currents induced by coapplication of $30 \mu \mathrm{mol} / \mathrm{L}$ acetylcholine (95\% confidence interval $[\mathrm{Cl}]$ ). For Denervation or Control group, drug $\mathrm{IC}_{50}$ values that do not share a superscript are statistically different from each other by one-way analysis of variance and Tukey's multiple comparison method.

we found that the slope conductance of $\varepsilon-\mathrm{AChR}$ expressed in Xenopus laevis oocytes was different from that in skeletal mus$\mathrm{cle}^{[15,16]}$.

We applied a holding voltage of $-80 \mathrm{mV}$ because the antagonistic effects of NDMRs are independent of holding voltages ranging from -100 to $-40 \mathrm{mV}^{[17,18]}$. Jonsson Fagerlund et a ${ }^{[19]}$ reported that repeated applications of $10 \mu \mathrm{mol} / \mathrm{L}$ acetylcholine desensitized the receptor, and they suggested that the decrease in the $\mathrm{IC}_{50}$ values of NDMRs could be at least partly explained by receptor desensitization. However, in Paul's work $^{[13]}$ and in this study, $10 \mu \mathrm{mol} / \mathrm{L}$ or $30 \mu \mathrm{mol} / \mathrm{L}$ acetylcholine concentrations were selected because these concentrations were close to the $\mathrm{EC}_{50}$ concentration for the innervated skeletal muscle and thus more physiologically relevant than lower acetylcholine concentrations. Additionally, measurement of the control current caused by ACh alone was repeated after washout of the vecuronium in both Paul's work ${ }^{[13]}$ and in this study. After taking the mean value of these two ACh applications and using this value as the average control current, the antagonist response was calculated by use of the above equation. Through this method, we can minimize the effect of receptor desensitization on the results.

The same ACh concentration applied here produced larger inward currents in nAChRs in skeletal muscle after denervation than in the innervated control. This leads us to suggest, in accordance with the views of others ${ }^{[20,21]}$, that skeletal muscles deprived of their motor nerves develop an increased sensitivity to ACh.

Consistent with previous reports ${ }^{[9,22]}$, the $\mathrm{IC}_{50}$ values of vecuronium increased after denervation, indicating that denervation caused resistance to NDMRs. One potential mechanism for this resistance could be that denervation induces the up-regulation of mature and immature $\mathrm{nAChR}$ on the muscle membrane, which would increase the amount of NDMR 

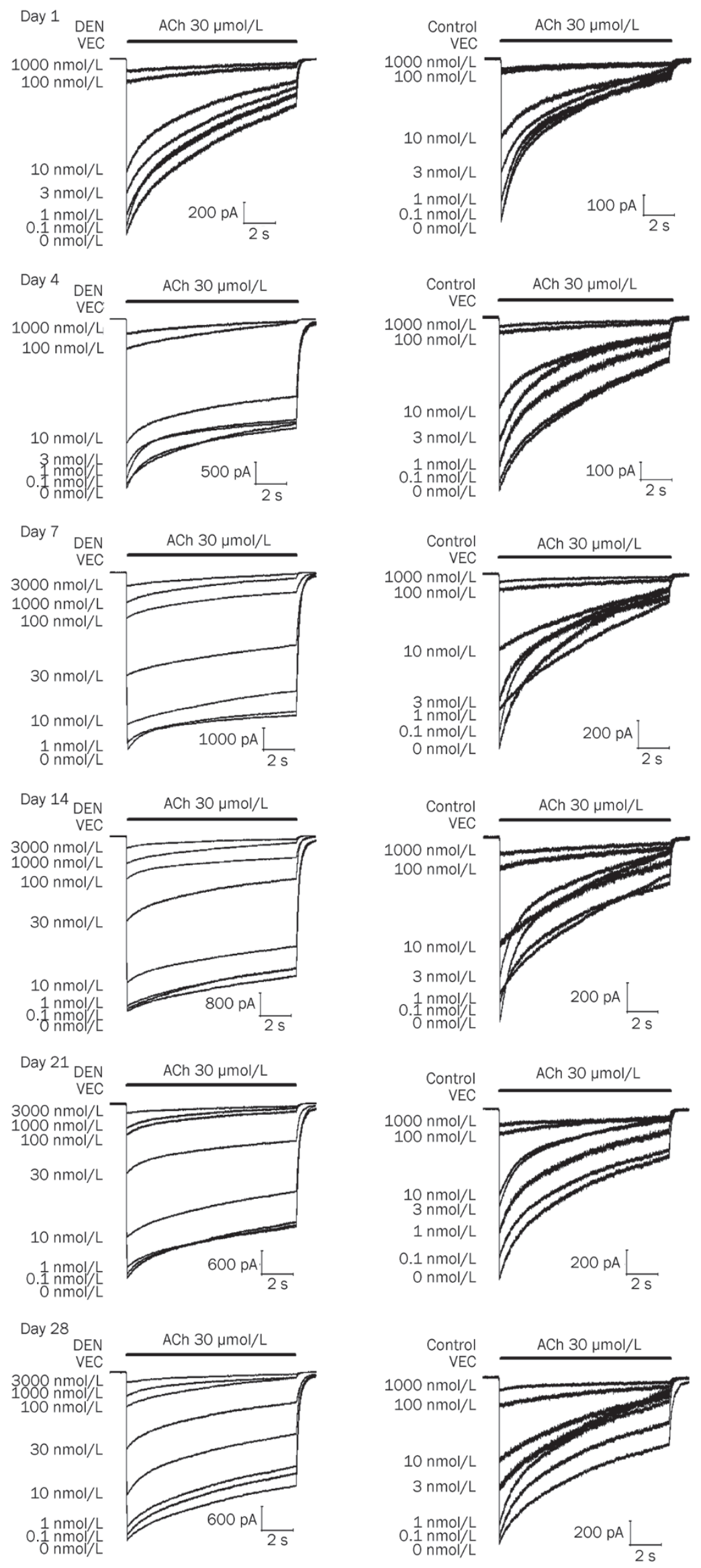

Figure 3. Concentration-dependent effects of vecuronium on nicotinic acetylcholine receptors (nAChRs) in denervated (DEN) and innervated (Control) muscle cells at Day 1, 4, 7, 14, 21, and 28 after denervation. 

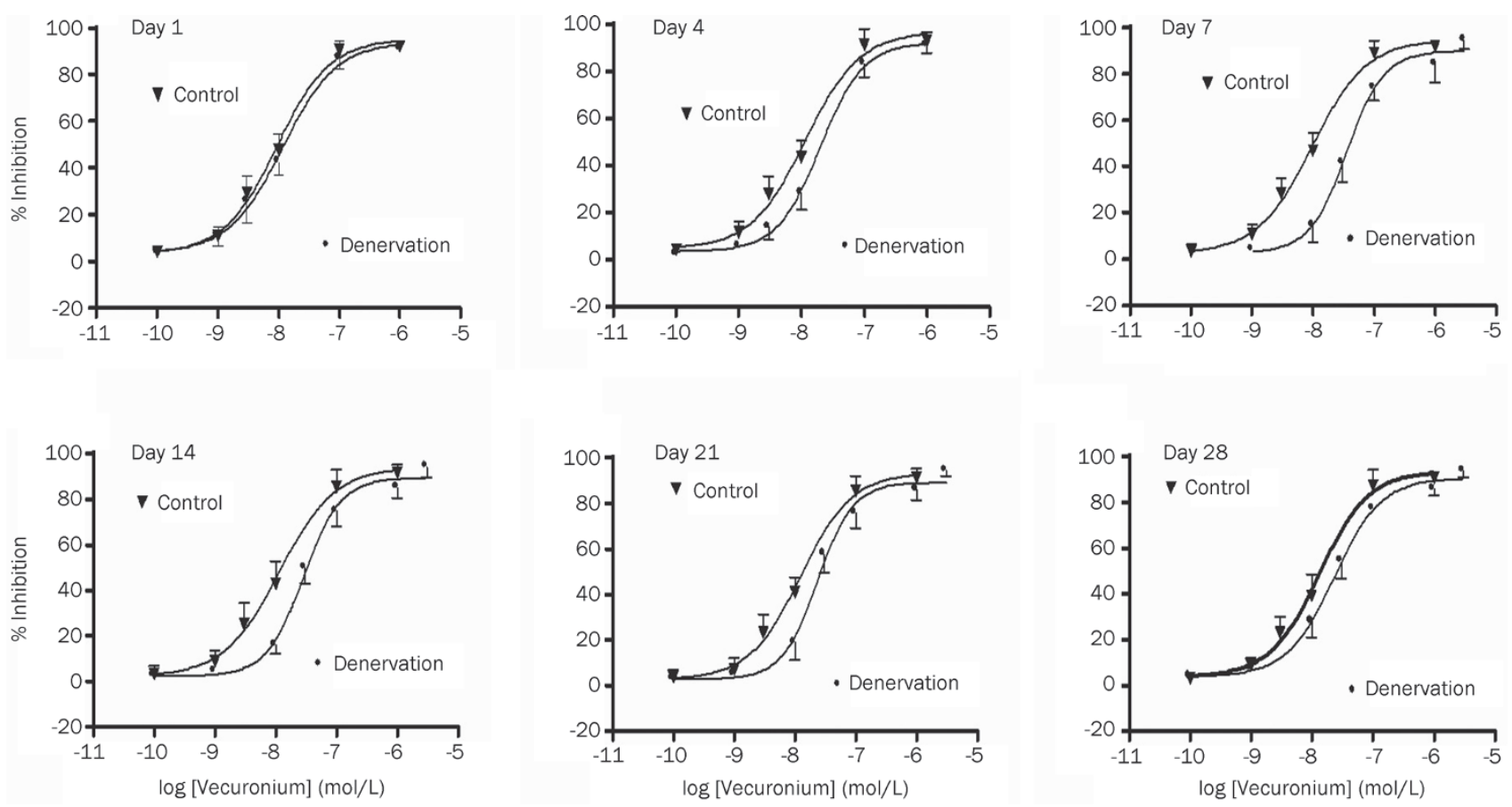

Figure 4. Concentration-response effects of vecuronium looking at inhibition of acetylcholine-induced currents in denervated and control (innervated) skeletal muscle cells at Day 1, 4, 7, 14, 21, and 28 after denervation. Data points show means \pm SD (error bars) of five muscle cells taken from at least two mice. Error bars not visible are smaller than symbols.

required to competitively block $\mathrm{ACh}^{[3]}$. However, reports of changes in $\mathrm{nAChR}$ numbers at Day 1 have been conflicting. Tsay and Schmidt ${ }^{[23]}$ reported a sharp increase in the transcriptional activity of AChR subunit genes beginning after approximately half a day after denervation of chick skeletal muscle. However, Ibebunjo and Martyn ${ }^{[9,24]}$ found no changes in $\mathrm{nAChR}$ numbers at Day 1 after a burn, and they also observed that skeletal muscle at Day 1 post-burn was resistant to dTC in rats. However, our study showed that skeletal muscle did not become resistant to vecuronium at Day 1 after denervation. Wang et al ${ }^{[25]}$ observed that post-denervation resistance to atracurium was greater than to vecuronium, which is due to the different potencies of atracurium and vecuronium on $\mathrm{nAChR}$ subunits. In addition to having a similar structure to that of atracurium, dTC also has less potency on $\gamma$-AChR than on $\varepsilon$-AChR and has partial agonist effects on $\mathrm{\gamma}$-AChR ${ }^{[13,18,26]}$. Thus, the occurrence of these differences in resistance to NDMRs at Day 1 after denervation may be associated with the different potencies of the NDMRs on nAChR subtypes and not with changes in the amount of nAChRs after denervation.

Resistance to vecuronium appeared at Day 4, peaked at Day 7, and declined by Day 14. These findings are paralleled by changes in nAChRs and $\gamma$-AChR on the same days after denervation, as shown by other research ${ }^{[9,10,24]}$. Although the $\mathrm{IC}_{50}$ values of vecuronium further decreased after Day 14 , the $\mathrm{IC}_{50}$ values at Day 28 remained significantly higher for denervated cells than for the innervated control cells, which indicated that the resistance to NDMRs had not disappeared at Day 28. Con- sistent with our results, Adams et a $l^{[11]}$ observed an increase in nAChR RNA levels during the first month of denervation, and the level began to return to the innervated level beyond one month after denervation. However, Ma et al ${ }^{[10]}$ found that the expression of most of the nAChR subunits returned to the control level within one month after denervation.

In summary, short-term muscle denervation leads to a changing pattern of resistance to NDMRs that can be attributed to up-regulation of mature and immature $\mathrm{nAChRs}$ on the muscle membrane. After denervation, resistance to vecuronium appeared by Day 4, peaked at Day 7, declined by Day 14, and persisted through Day 28. Our findings suggest that the dose requirement of NDMRs after denervation to achieve clinically appropriate muscle relaxation changes during the first month after denervation.

\section{Acknowledgements}

This work was supported by the National Natural Science Foundation of China (№ 30571796).

We thank Dr Xin-qiu LIU (Department of Neurobiology, School of Medicine, Shanghai JiaoTong University) for technical assistance and strong support.

\section{Author contribution}

Hong WANG and Shi-tong LI designed the research; Hong WANG and Bin YANG performed the research; Hong WANG and Guang-wei HAN analyzed the data; and Hong WANG and Shi-tong LI wrote the paper. 


\section{Abbreviation}

NDMRs, nondepolarizing muscle relaxants; $\mathrm{nAChR}$, nicotinic acetylcholine receptor; $\mathrm{\gamma}$-AChR, fetal-type nicotinic acetylcholine receptor; $\varepsilon-\mathrm{AChR}$, adult-type nicotinic acetylcholine receptor; $\mathrm{IC}_{50}$, inhibitory concentration resulting in a half-maximal response; dTC, d-tubocurarine; FDB, flexor digitorum brevis; DMEM, Dulbecco's modified Eagle's medium; ACh, Acetylcholine; VEC, vecuronium

\section{References}

1 Mishina M, Takai T, Imoto K, Noda M, Takahashi T, Numa S, et al. Molecular distinction between fetal and adult forms of muscle acetylcholine receptor. Nature 1986; 321: 406-11.

$2 \mathrm{Gu}$ Y, Hall ZW. Characterization of acetylcholine receptor subunits in developing and in denervated mammalian muscle. J Biol Chem 1988; 263: 12878-85.

3 Martyn JA, White DA, Gronert GA, Jaffe RS, Ward JM. Up-and-down regulation of skeletal muscle acetylcholine receptors: effects on neuromuscular blockers. Anesthesiology 1992; 76: 822-43.

4 Witzemann V, Brenner HR, Sakmann B. Neural factors regulate AChR subunit mRNAs at rat neuromuscular synapses. J Cell Biol 1991; 114: $125-41$.

5 Hogue CW Jr, Itani MS, Martyn JA. Resistance to d-tubocurarine in lower motor neuron injury is related to increased acetylcholine receptors at the neuromuscular junction. Anesthesiology 1990; 73: 703-9.

6 Kim C, Martyn J, Fuke N. Burn injury to trunk of rat causes denervation-like responses in the gastrocnemius muscle. J Appl Physiol 1988; 65: 1745-51.

7 Yanez P, Martyn JA. Prolonged D-tubocurarine infusion and/or immobilization causes upregulation of acetylcholine receptors and hyperkalemia to succinylcholine. Anesthesiology 1996; 84: 384-91.

8 Nosek MT, Martyn JA. $\mathrm{Na}^{+}$channel and acetylcholine receptor changes in muscle at sites distant from burns do not simulate denervation. J Appl Physiol 1997; 82: 1333-9.

9 Ibebunjo C, Martyn JA. Thermal injury induces greater resistance to $d$-tubocurarine in local rather than in distant muscles in the rat. Anesth Analg 2000; 91: 1243-9.

10 Ma J, Shen J, Garrett JP, Lee CA, Li Z, Elsaidi GA, et al. Gene expression of myogenic regulatory factors, nicotinic acetylcholine receptor subunits, and GAP-43 in skeletal muscle following denervation in a rat model. J Orthop Res 2007; 25: 1498-505.

11 Adams L, Carlson BM, Henderson L, Goldman D. Adaptation of nicotinic acetylcholine receptor, myogenin, and MRF4 gene expression to long-term muscle denervation. J Cell Biol 1995; 131: 1341-9.

12 Hamill OP, Marty A, Neher E, Sakmann B, Siqworth FJ. Improved patch-clamp techniques for high-resolution current recording from cells and cell-free membrane patches. Pflugers Arch 1981; 391 : 85-100.

13 Paul M, Kindler CH, Fokt RM, Dresser MJ, Dipp NC, Yost CS. The potency of new muscle relaxants on recombinant muscle-type acetylcholine receptors. Anesth Analg 2002; 94: 597-603.

14 Kindler CH, Verotta D, Gray AT, Gropper MA, Yost CS. Additive inhibition of nicotinic acetylcholine receptors by corticosteroids and the neuromuscular blocking drug vecuronium. Anesthesiology 2000; 92: 821-32.

15 Yost CS, Wineqar BD. Potency of agonists and competitive antagonists on adult- and fetal-type nicotinic acetylcholine receptors. Cell Mol Neurobiol 1997; 17: 35-50.

16 Villarroel A, Sakmann B. Calcium permeability increase of endplate channels in rat muscle during postnatal development. J Physiol 1996; 496: 331-8.

17 Garland CM, Foreman RC, Chad JE, Hold-Dye L, Walker RJ. The actions of muscle relaxants at nicotinic acetylcholine receptor isoforms. Eur J Pharmacol 1988; 357: 83-92.

18 Fletcher GH, Steinbach JH. Ability of nondepolarizing neuromuscular blocking drugs to act as partial agonists at fetal and adult mouse muscle nicotinic receptor. Mol Pharmacol 1996; 49: 938-47.

19 Jonsson Fagerlund M, Dabrowski M, Eriksson LI. Pharmacological characteristics of the inhibition of nondepolarizing neuromuscular blocking agents at human adult muscle nicotinic acetylcholine receptor. Anesthesiology 2009; 110: 1244-52.

20 Axelsson J, Thesleff S. A study of supersensitivity in denervated mammalian skeletal muscle. J Physiol 1959; 147: 178-93.

21 Martyn JA, Richtsfeld M. Succinylcholine-induced hyperkalemia in acquired pathologic states: etiologic factors and molecular mechanisms. Anesthesiology 2006; 104: 158-69.

22 Han T, Kim H, Bae J, Kim K, Martyn JA. Neuromuscular pharmacodynamics of rocuronium in patients with major burns. Anesth Analg 2004; 99: 386-92.

23 Tsay HJ, Schmidt J. Skeletal muscle denervation activates acetylcholine receptor genes. J Cell Biol 1989; 108: 1523-6.

24 Ibebunjo C, Martyn J. Disparate dysfunction of skeletal muscles located near and distant from burn site in the rat. Muscle Nerve 2001; 24: 1283-94.

25 Wang $H$, Yang B, Xu YF, Yan T, Li ST. Magnitude differences of resistance to different nondepolarizing muscle relaxants in the denervated mouse skeletal muscle. Acta Pharmacol Sin 2010; 31: 399-404.

26 Steinbach JH, Chen Q. Antagonist and partial agonist action of d-tubocurarine at mammalian muscle acetylcholine receptors. J Neurosci 1995; 15: 230-40. 